\title{
MATLAB as an Alternative for Speed Control of Direct Current Motor without having Actual Lab
}

\author{
Abhinav V. Deshpande \\ Internal Full Time (IFT) Ph. D. Research Scholar, School of Electronics Engineering (SENSE) \\ Vellore Institute of Technology (VIT), Vellore, Tamil Nadu, India-632014 \\ avd.a.deshpande@gmail.com
}

\begin{abstract}
The main aim of this research paper is to introduce the modeling of power components and to facilitate computer simulation as an application tool for conducting transient and control studies. The simulation can be very helpful in gaining insights to the dynamic behaviour and interactions that are often not readily apparent from reading theory. Next to having an actual system is to experiment on. In this research paper, the block diagram of a Direct Current (DC) motor was developed and by using Simulink, a toolbox extension of the MATLAB program, the block diagram was simulated with the expected waveforms output. Moreover, by varying certain constraints of the DC motor block diagram, the resultant waveform of the simulation will change accordingly. These constraints include the field current, armature circuit resistance and the armature voltage. The simulation and modeling of the DC motor also gave a deep look into the expected output when testing the actual DC motor. The results from the simulation were never likely to occur in the real-life condition due to the response times and the condition of the actual motor. The MATLAB and the SIMULINK is used because of the short learning curve, its wide distribution and its general-purpose nature. This will demonstrate the advantages of using MATLAB for analyzing the power system steady state behaviour and its capabilities for simulating the transients in the power systems and power electronics, including the control system dynamic behaviour.
\end{abstract}

Keywords - MATLAB; Simulink; Direct Current Motor; Speed Control; Armature

\section{Introduction}

The theory of the electrical circuit represents one of the most important parts of any electrical engineering education. The main aim of this research paper is to obtain the knowledge of circuit analysis and synthesis and to experience the actual behaviour of a DC motor. This requires a powerful software mathematical tool. MATLAB is a software for high performance computation and visualization. The combination of the analysis makes MATLAB, a premier software package for all computer , electronic and electrical engineers. The performance of MATLAB has been improved by SIMULINK program, which is a graphical mouse driven program for the simulation of dynamic system. It enables the user to simulate linear as well as nonlinear system easily and efficiently. A theory is a general statement of principle abstracted from the observations and a model is a representation of a theory that can be used for the control and prediction. For a model in order to be useful, it must be realistic and yet simple enough to understand and manipulate. These requirements are not easily fulfilled as the realistic models are seldom simple and simple models are seldom realistic. The scope of the model is defined by what is considered relevant. The feature or the behaviour that is relevant must be included in the model and those that are not can be ignored. Modeling refers to the process of analysis and synthesis in order to arrive at a mathematical description that contains the relevant dynamic characteristics of the particular model.

\subsection{Modeling and Simulation}

The modeling and simulation of this research project helped to generate the expected outcomes of the project design. The program used was called as the SIMULINK, a sub program of the mathematical and simulation software called as MATLAB. This software is used to provide the simulation design and results for the evaluation of the transient response of a DC motor.

\subsection{Aim of the Research}

The main aim of this research paper is to evaluate the transient response of a DC motor by using MATLAB/SIMULINK. These can be achieved by changing the setting in MATLAB/SIMULINK in order to investigate the motor responds to these changes. This would allow future student to use this SIMULINK program in order to evaluate the transient response of a DC motor without having to go to the laboratory in order to use the actual DC motor.

\section{Motor Modeling and Simulation}

In order to perform the simulation of a system, appropriate model needs to be established. For this research paper, this system contains a DC motor. Therefore, a model which is based on the motor specification needs to be obtained.

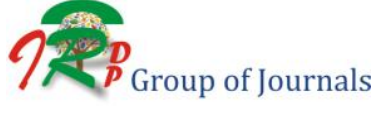




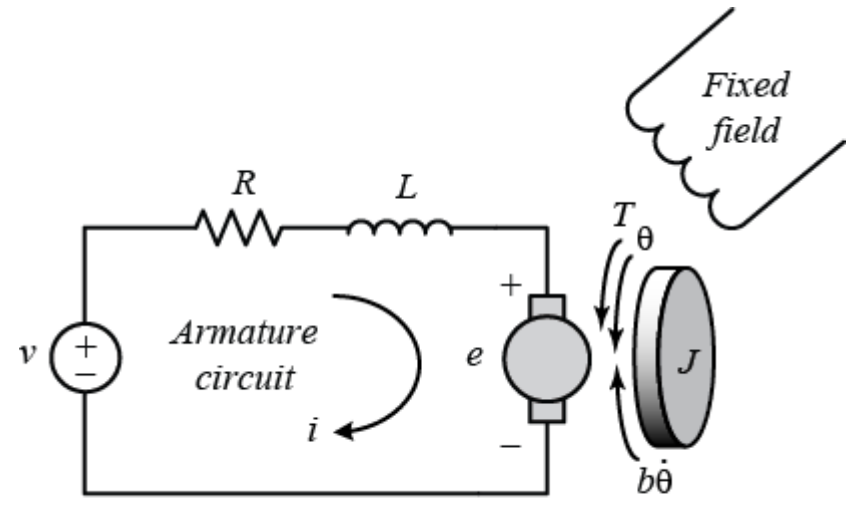

Rotor

Fig. 1: Circuit Diagram of a DC Motor

Assuming magnetic linearity, the basic motor equations are given as below:

$\mathrm{T}=\mathrm{K}_{\mathrm{f}} \mathrm{i}_{\mathrm{f}} \mathrm{i}_{\mathrm{a}}$

Eqn. (1)

$\mathrm{E}_{\mathrm{a}}=\mathrm{K}_{\mathrm{f}} \mathrm{i}_{\mathrm{f}} \omega_{\mathrm{a}}$

Eqn. (2)

where $K_{m}=K_{f} i_{f}$ is a constant, which is also the ratio $e_{a} / e_{m}$

The Laplace transforms of Eqn. (1) and Eqn. (2) are given as below:

$\mathrm{T}(\mathrm{s})=\mathrm{K}_{\mathrm{m}} \mathrm{i}_{\mathrm{a}}(\mathrm{s})$

Eqn. (3)

$\mathrm{E}_{\mathrm{a}}=\mathrm{K}_{\mathrm{a}} \omega_{\mathrm{m}}(\mathrm{s})$

Eqn. (4)

Let the switch SW be closed at the time $\mathrm{t}=0$.

After the switch is closed

$\mathrm{V}_{\mathrm{t}}=\mathrm{e}_{\mathrm{a}}+\mathrm{R}_{\mathrm{a}} \mathrm{i}_{\mathrm{a}}+\mathrm{L}_{\mathrm{eq}} \mathrm{di}_{\mathrm{a}} / \mathrm{dt}$

Eqn. (5)

From Eqn. (2) and Eqn. (5), we have

$\mathrm{V}_{\mathrm{t}}=\mathrm{K}_{\mathrm{m}} \omega_{\mathrm{m}}+\mathrm{R}_{\mathrm{a}} \mathrm{i}_{\mathrm{a}}+\mathrm{L}_{\mathrm{eq}} \mathrm{di}_{\mathrm{a}} / \mathrm{dt}$

The Laplace transform of Eqn. (6) for zero initial conditions is given as below:

$\mathrm{V}_{\mathrm{t}}(\mathrm{s})=\mathrm{K}_{\mathrm{m}} \omega_{\mathrm{m}}(\mathrm{s})+\mathrm{R}_{\mathrm{a}} \mathrm{I}_{\mathrm{a}}(\mathrm{s})+\mathrm{L}_{\mathrm{eq}}(\mathrm{s}) \mathrm{I}_{\mathrm{a}}(\mathrm{s})$

Eqn. (7) or

$\mathrm{V}_{\mathrm{t}}(\mathrm{s})=\mathrm{K}_{\mathrm{m}} \omega_{\mathrm{m}}(\mathrm{s})+\mathrm{I}_{\mathrm{a}}(\mathrm{s}) \mathrm{R}_{\mathrm{a}}\left(1+\mathrm{s} \tau_{\mathrm{a}}\right)$

Eqn. (8)

where $\tau_{\mathrm{a}}=\mathrm{L}_{\mathrm{eq}} / \mathrm{R}_{\mathrm{a}}$ is the electrical time constant of the armature.

The dynamic equation for the mechanical system is given as below:

$\mathrm{T}=\mathrm{K}_{\mathrm{m}} \mathrm{i}_{\mathrm{a}}=\mathrm{J} \mathrm{d} \omega_{\mathrm{m}} / \mathrm{dt}+\mathrm{B} \omega_{\mathrm{m}}+\mathrm{T}_{\mathrm{L}}$

Eqn. (9)

The term $\mathrm{B} \omega_{\mathrm{m}}$ represents therotational loss torque of the system.

The Laplace transform of Eqn. (6) is given as below: $\mathrm{T}(\mathrm{s})=\mathrm{K}_{\mathrm{m}} \mathrm{i}_{\mathrm{a}}(\mathrm{s})=\mathrm{J}(\mathrm{s}) \omega_{\mathrm{m}}(\mathrm{s})+\mathrm{B} \omega_{\mathrm{m}}(\mathrm{s})+\mathrm{T}_{\mathrm{L}}(\mathrm{s}) \quad$ Eqn. (10) Therefore, from the Eqn. (10) and Eqn. (3), it can be concluded that

$\omega_{\mathrm{m}}=\mathrm{T}(\mathrm{s})-\mathrm{T}_{\mathrm{L}}(\mathrm{s}) / \mathrm{B}(1+\mathrm{S} \mathrm{J} / \mathrm{B})=\mathrm{K}_{\mathrm{m}} \mathrm{I}_{\mathrm{a}}(\mathrm{s})-\mathrm{T}_{\mathrm{L}}(\mathrm{s})$ Eqn. (11) where $\tau_{\mathrm{m}}=\mathrm{J} / \mathrm{B}$ is the mechanical time constant of the system

Therefore from Eqn. (4) and Eqn. (8), it can be concluded that

$\mathrm{I}_{\mathrm{a}}(\mathrm{s})=\mathrm{V}_{\mathrm{t}}(\mathrm{s})-\mathrm{E}_{0}(\mathrm{~s}) / \mathrm{R}_{\mathrm{a}}\left(1+\mathrm{s} \tau_{\mathrm{a}}\right)=\mathrm{V}_{\mathrm{t}}(\mathrm{s})-\mathrm{K}_{\mathrm{m}} \omega_{\mathrm{m}}(\mathrm{s}) / \mathrm{R}_{\mathrm{a}}(1$ $\left.+\mathrm{s} \tau_{\mathrm{a}}\right)$

Eqn.(12)

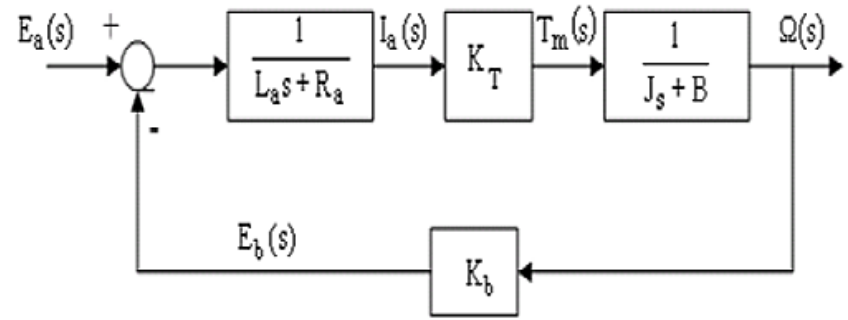

Fig.2: Block Diagram Representation of a Separately Excited DC Motor

\section{Lab Work}

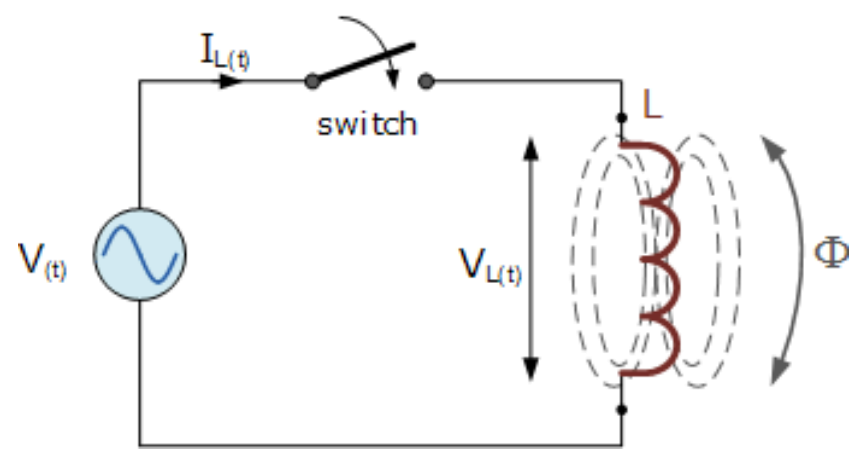

Fig.3: Circuit Diagram for finding the Inductance (L) and Resistance (R)

Given that $\mathrm{R}_{\mathrm{a}}=1.9 \mathrm{~K}$

\subsection{Observation Table}

Table 1: Observation Table for Calculating the Torque, Speed and Current of a Separately Excited DC Shunt Motor

\begin{tabular}{|c|c|c|c|c|c|}
\hline Sr. No. & $\mathbf{V}$ & $\mathbf{I}$ & $\begin{array}{c}\mathbf{Z}= \\
\mathbf{V} / \mathbf{I}\end{array}$ & $\begin{array}{c}\mathbf{X}=\mathbf{( Z )}^{\mathbf{2}} \\
\left.-\mathbf{R}^{\mathbf{2}}\right)^{\mathbf{1} 2}\end{array}$ & $\begin{array}{c}\mathbf{L}= \\
\mathbf{X} / \mathbf{2} \boldsymbol{\pi} \mathbf{F}\end{array}$ \\
\hline 1 & 5.74 & 1 & 5.74 & 5.37 & 0.0171 \\
\hline 2 & 4.60 & 0.82 & 5.60 & 5.27 & 0.0168 \\
\hline Average & 5.17 & 0.91 & 5.67 & 5.32 & 0.017 \\
\hline
\end{tabular}

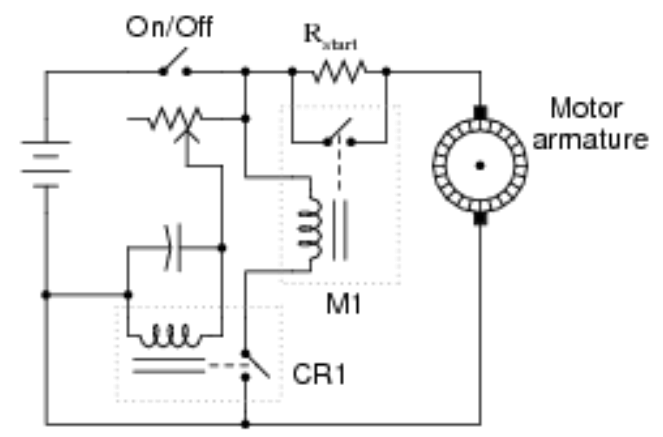

Fig. 4: Circuit Diagram for Calculating the Torque, Speed and Current of a Separately Excited DC Shunt Motor 
Table 2: Observation Table for Calculating the Torque, Speed and Current for a Separately Excited DC Shunt Motor

\begin{tabular}{|c|c|c|c|c|c|}
\hline $\begin{array}{l}\text { Sr. } \\
\text { No. }\end{array}$ & $\begin{array}{c}\text { Intern } \\
\text { al } \\
\text { EMF } \\
\text { (Volts) }\end{array}$ & $\begin{array}{l}\text { Speed } \\
(\mathbf{r p m})\end{array}$ & $\begin{array}{c}\text { Current } \\
\mathbf{I}_{\mathrm{a}}(\text { Amp) }\end{array}$ & $\begin{array}{c}W_{m}= \\
2 \pi N / 60 \\
(\mathrm{rad} / \mathrm{sec})\end{array}$ & $\begin{array}{c}K_{m}= \\
E_{a} / W_{m}\end{array}$ \\
\hline 1 & 140 & 670 & 1.9 & 70.16 & 1.99 \\
\hline 2 & 150 & 720 & 2.1 & 75.39 & 1.98 \\
\hline 3 & 160 & 750 & 2.25 & 78.53 & 2.03 \\
\hline 4 & 170 & 780 & 2.4 & 81.68 & 2.08 \\
\hline 5 & 183 & 870 & 2.55 & 91.10 & 2.0 \\
\hline $\begin{array}{c}\text { Avera } \\
\text { ge }\end{array}$ & 160.06 & 758 & 2.24 & 79.37 & 2.016 \\
\hline
\end{tabular}

Table 3: Specifications of a DC Motor

\begin{tabular}{|c|c|}
\hline Winding & Shunt \\
\hline Armature Voltage & 230 Volts \\
\hline Armature Current & 29 Amperes \\
\hline Power & $7.5 \mathrm{HP}$ \\
\hline RPM & $1000 \mathrm{RPM}$ \\
\hline
\end{tabular}

Looking at the mechanical Equation which is Eqn. (9), it can be concluded that

$\mathrm{K}_{\mathrm{m}} \mathrm{I}_{\mathrm{a}}=\mathrm{Jd} \omega_{\mathrm{m}} / \mathrm{dt}+\mathrm{B} \omega_{\mathrm{m}}+\mathrm{T}_{1}$ Eqn. (13)

$\mathrm{J} \mathrm{d} \omega_{\mathrm{m}} / \mathrm{dt}=\mathrm{K}_{\mathrm{m}} \mathrm{I}_{\mathrm{a}}-\mathrm{B} \omega_{\mathrm{m}}-\mathrm{T}_{1}$

Eqn. (14)

At the steady state both $I_{a}$ and $\omega_{m}$ stabilized, then we have $\mathrm{d} \omega_{\mathrm{m}} / \mathrm{dt}=0$

Eqn. (15)

$\mathrm{K}_{\mathrm{m}} \mathrm{I}_{\mathrm{a}}-\mathrm{B} \omega_{\mathrm{m}}-\mathrm{T}_{1}=0$

Eqn. (16)

Since $\mathrm{P}=7.5 \mathrm{hp}, \mathrm{I}_{\mathrm{a}}=29$ Amperes, $\mathrm{K}_{\mathrm{m}}=2.19, \mathrm{n}=1000$ rpm

As the speed is in terms of $\mathrm{N}$, so the unit is rpm. We need to convert it to $\mathrm{rad} / \mathrm{sec}$ by using the following formulae which are given as below:

$\mathrm{W}_{\mathrm{m}}=2 \pi \mathrm{n} / 60$

Eqn. (17)

$\mathrm{W}_{\mathrm{m}}=2 \pi^{*} 1000 / 60=104.66 \mathrm{rad} / \mathrm{sec}$

Eqn. (18)

$\mathrm{T}_{1}=\mathrm{P} / \mathrm{W}=7.5 * 746 / 104.66(1 \mathrm{HP}=746 \mathrm{Watts})=53.46 \mathrm{~N}-$ $\mathrm{m}$

Eqn. (19)

Therefore, we have

$(2.19 * 29)-\mathrm{B} * 104.66-\mathrm{T}_{1}=0$

Eqn. (20)

$(2.19 * 29)-\mathrm{B} * 104.66-53.46=0$

$\mathrm{B}=0.096$

Eqn. (22)

For the value of the rotor inertia $\mathbf{J}\left(\right.$ in $\mathrm{Kgm}^{2}$ )

It is assumed to be $0.04 \mathrm{Kgm}^{2}$

With the required specification of a DC motor, a model of the DC motor was developed by using the SIMULINK. The DC motor was modeled by using the characteristics. The transfer function of the electrical and the mechanical networks of the motor is shown in the figure below:

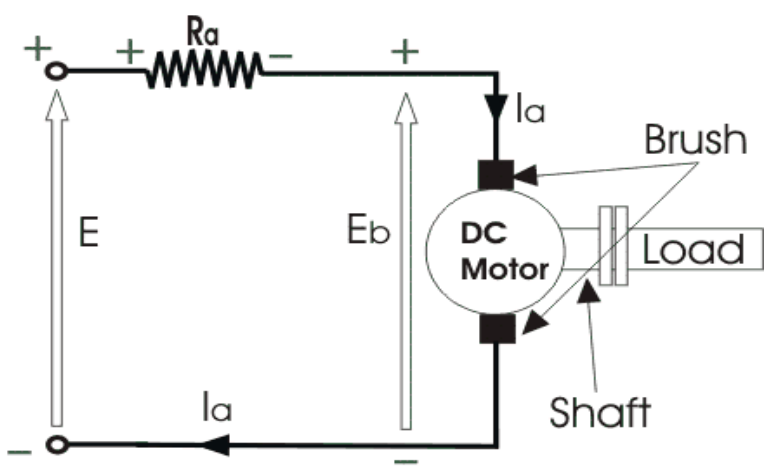

Fig. 5: Block Diagram of DC Shunt Motor

The above figure shows the DC motor input armature voltage $\left(V_{t}\right)$ which is summed with the internal EMF. The result is then fed into the electrical characteristics transfer function block in order to produce the armature current $\left(\mathrm{I}_{\mathrm{a}}\right)$. It is then passed through a torque constant in order to produce the torque. This is then summed with a torque load giving an output torque which is then fed into the mechanical characteristics transfer function block. The output power is the rotor speed $\left(\mathrm{W}_{\mathrm{m}}\right)$, which is fed back into the speed constant providing the constant EMF.

\section{Simulated Results versus Measured Results}

As can be seen from the block diagram, the different values of the applied voltage were simulated in order to get the following results. The tests were also done on the actual DC motor by using a workbench to get the armature current, torque and the rotor speed readings.

Table 4: Simulated Results versus Measured Results of a DC Shunt Motor

\begin{tabular}{|c|c|c|c|c|c|c|c|}
\hline $\begin{array}{c}\text { Sr. } \\
\text { No. }\end{array}$ & $\begin{array}{c}\text { Volt } \\
\text { age } \\
\text { Appl } \\
\text { ied }\end{array}$ & $\begin{array}{c}\text { Arma } \\
\text { ture } \\
\text { Curre } \\
\text { nt }\left(\mathbf{I}_{\mathbf{a}}\right)\end{array}$ & $\begin{array}{c}\text { Torq } \\
\mathbf{u e} \\
(\mathbf{T})\end{array}$ & $\begin{array}{c}\text { Roto } \\
\mathbf{r} \\
\text { Spee } \\
\mathbf{d} \\
\left.\mathbf{N}_{\mathbf{r}}\right)\end{array}$ & $\begin{array}{c}\text { Arm } \\
\text { ature } \\
\mathbf{C u r r} \\
\mathbf{e n t} \\
\left(\mathbf{I}_{\mathbf{a}}\right)\end{array}$ & $\begin{array}{c}\text { Tor } \\
\text { que } \\
(\mathbf{T})\end{array}$ & $\begin{array}{c}\text { Roto } \\
\mathbf{r} \\
\text { Spee } \\
\mathbf{d} \\
\left.\mathbf{( N}_{\mathbf{r}}\right)\end{array}$ \\
\hline 1. & 183 & 4.239 & 8.435 & $\begin{array}{c}87.9 \\
1\end{array}$ & 2.55 & 5.12 & 91.10 \\
\hline 2. & 170 & 3.938 & 7.836 & $\begin{array}{c}81.6 \\
7\end{array}$ & 2.40 & 4.99 & 81.68 \\
\hline 3. & 160 & 3.706 & 7.375 & $\begin{array}{c}76.8 \\
6\end{array}$ & 2.25 & 4.58 & 78.53 \\
\hline 5. & 140 & 3.243 & 6.453 & 67.2 & 1.90 & 3.79 & 70.16 \\
\hline
\end{tabular}

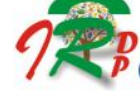


From the results, it can be seen that the simulated readings were slightly similar to the measured readings. The difference could be put down for not having accurate initial parameters for the simulation and due to the assumption of J. Thus, the simulation of a DC motor has been performed and the transient response is obtained with the help of MATLAB.

\section{Conclusion}

The actual experimentation on bulky power components can be expensive and time consuming. But the simulation offers a fast and inexpensive means to learn more about this component. In this research project, the block diagram of a DC motor was developed and by using the SIMULINK, a toolbox extension of the MATLAB program, the block diagram was simulated with the expected waveform output. Furthermore, by verifying certain parameters of the DC motor block diagram, the output waveform of the simulation would change accordingly. This parameter includes the field current, the armature circuit resistance and the armature voltage. The simulation and modeling of the DC motor also gave aninside look of the expected output when testing the actual DC motor. The results from the simulation were never likely to occur in the real-life condition due to the response times and the conditions of the actual motor.

\section{References}

[1] MathWorks. (2001). Introduction to MATLAB. The MathWorks, Inc. Available: http://www.mathworks.com/ helpdesk/help/techdoc /learn_MATLAB/ch1intro.shtml\#22671.

[2] MathWorks. (2001). SIMULINK. The MathWorks, Inc. Available: http://www.mathworks.com/access/helpdesk/help/toolbox/SIMULI NK.

[3] MathWorks (2001). What is SIMULINK. The MathWorks, Inc. Available: http://www.mathworks.com/access/helpdesk/help/ toolbox/SIMULINK/ug/ug.s html

[4] MathWorks (2000). Using MATLAB Version 6. The MathWorks, Inc. Available: http://www.mathworks.com/access/helpdesk/help /pdf_doc/MATLAB/using_ml.pdf

[5] The MathWorks. MATLAB Student Version Learning MATLAB 6 (Release 12), $2^{\text {nd }}$ Printing, January 2001.

[6] P. C. Sen, "Principles of Electric Machines and Power Electronics ( $2^{\text {nd }}$ Edition), John Wiley and Sons Inc., 198949.

[7] G. R. Slemon and A. Straughen, "Electric Machines", AddisonWesley Publishing Company, 1982.

[8] D. M. Etter, "Engineering Problem Solving with MATLAB", Prentice Hall, 1993.

[9] Chee-Mun Ong, "Dynamic Simulation of Electric Machinery", Prentice Hall PTR, 1998.

[10] Peter F. Ryff, David Platnick and Jose A. Karnas, "Electrical Machines and Transformers, Principles and Applications", Prentice Hall, Inc., 1987. 